\title{
EXPERIMENTAL RESEARCH ON EVOLUTION OVER TIME OF FIR TREE SAWDUST PELLETS
}

\author{
Iuliana Gageanu, Dan Cujbescu, Catalin Persu, Gabriel Gheorghe \\ National Institute of Research-Development for Machines and Installations \\ Designed to Agriculture and Food Industry, Romania \\ iulia.gageanu@gmail.com,dcujbescu@yahoo.com,persucatalin@yahoo.com, \\ gabrielvalentinghe@yahoo.com
}

\begin{abstract}
The technological process of biomass densification by pelleting has a number of special characteristics that fundamentally distinguish it from the densification of other types of materials, due to the fact that biomass densification is strongly influenced by a multitude of disruptive factors that need to be further studied. For this reason, it is important to take into account these disruptive factors in conducting experiments and interpreting data in a direct connection with the conditions for conducting experimental tests. In the practice of biomass densification, it was found that between the output parameters expressing the quality of pellets obtained and the accumulation of influencing factors represented by the properties of the material and compression conditions there is a strong link, regulating these factors is essential in obtaining a quality solid biofuel. The influence of these factors should be considered both during the process of biomass densification, as well as in the following period of time. The paper presents the results of monitoring pellets obtained from biomass pelleting experiments performed, represented by fir sawdust resulting from wood processing. Monitoring the evolution of the physical characteristics of pellets over time is a mandatory test for estimating the quality of pellets. The variation of the length of the pellets in time, from the exit from the formation process (the initial zero time) to the last day of following their evolution, is an important parameter that gives an overview of the stabilization tendencies of the pellets. The results obtained showed an average expansion between 0.62 and $0.82 \mathrm{~mm}$ for pellets obtained at $10 \%$ material moisture, a contraction between 0.61 and 1.55 for $13 \%$ material moisture and an even larger contraction, between 2.86 and $3.95 \mathrm{~mm}$, for $16 \%$ material moisture, depending on the compaction force used.
\end{abstract}

Keywords: fir sawdust, pelleting, length, durability.

\section{Introduction}

As the world aims to reduce the use of fossil fuels and replace them with renewable energy, the research was directed to the use of natural, renewable resources to obtain energy. Biomass was found to be a viable candidate for the production of biofuels in all three forms - solid, liquid and more recently gaseous [1-3]. Biomass was the first renewable resource to be used, as it has very similar combustion attributes as fossil fuels, but has the advantage that in grows every year and it can be made available yearlong.

Even if biomass can be used as it is for combustion, it would be more indicated to pass it through the processing stage, thus obtaining higher quality products. One of the easiest ways to obtain biofuels from biomass is to compress it, thus increasing the density, ensuring homogenous products [4-6]. Biomass materials are very diverse in terms of physical, chemical and biological properties, so it is difficult to focus on a single property in a given process [7-9].

The inherent properties of biomass are those that determine both the choice of conversion mode and any problems that may arise from processing. Equally, the choice of biomass source is influenced by the form in which energy is needed and this interconnection between the two aspects is what brings flexibility in the use of biomass as biofuel [10].

Densification processes and technologies are described together with the impact of the process, the variables of the raw material and the biochemical composition of the biomass on the attributes of the quality of the raw material such as durability, bulk density, pellet density and calorific value [11-12].

The process of forming pellets consists in subjecting the biomass to high pressures, during which time the particles are forced to agglomerate. A good understanding of the densification mechanisms that occur during and after the process is necessary in determining the quality of the resulting pellets by identifying the mechanisms by which the "binding" of biomass takes place. The nature of the interactions between particles in the densification process is particularly complex [13].

The quality of the densified biomass is given in part by the type of raw material and the process variables. These refer to those parameters, which are inherent in the pelleting process, namely, the dimensions of the die and its orifices, the pelleting speed the compression force, etc.

The paper presents the results from an experimental research of monitoring biomass pellets in time and determining the causes of changes that occurred in the monitoring period. 


\section{Materials and methods}

For monitoring of evolution of pellets in time and determining the causes for changes, pellets were obtained from biomass material represented by fir tree sawdust, that was grinded and sieved as to have dimensions smaller than $2 \mathrm{~mm}$. Pellets were obtained individually, using a single pelleting device (Figure 1) with an $8 \mathrm{~mm}$ orifice die, varying a series of parameters that affect both the process of obtaining the products and the quality of pellets when exiting the die and over time. The pelleting device was connected to a force machine, that was in turn connected to a computer, and through the means of the software it was possible to control the compaction force and the pelleting speed.
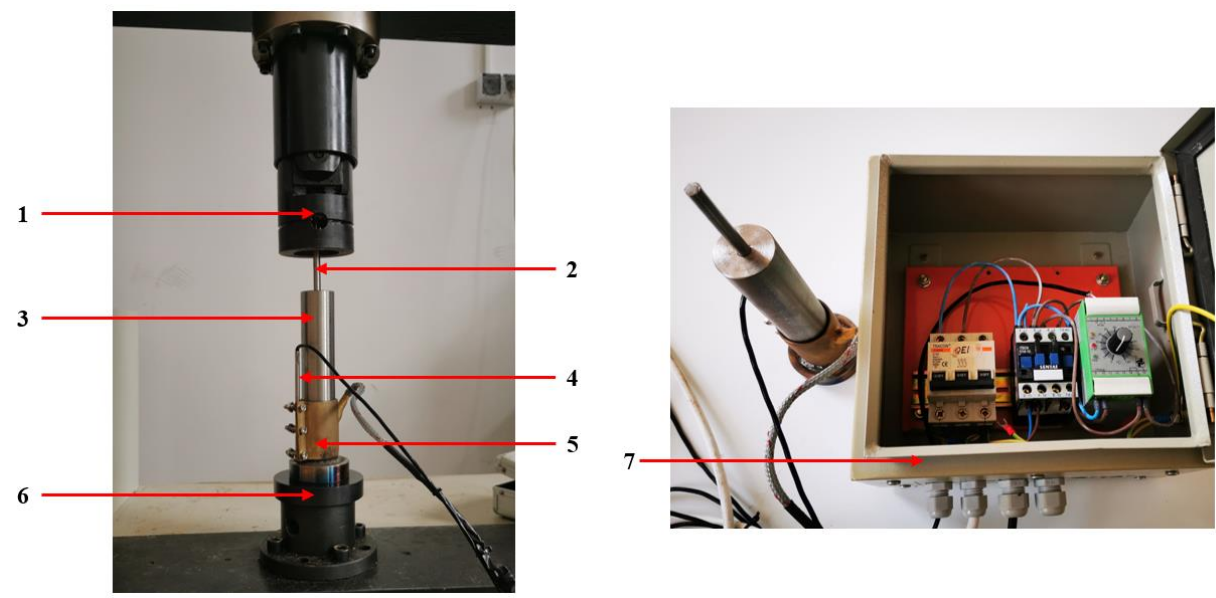

Fig. 1. Pelleting device: 1 - pressing head; 2 - piston; 3 - pelleting die; 4 - temperature sensor; 5 - heating element; 6 - blocking plate; 7 - automation box

The parameters varied were:

- initial material moisture: $10 \%, 13 \%, 16 \%$;

- pelleting force: $10 \mathrm{kN}, 20 \mathrm{kN}, 30 \mathrm{kN}$;

- pelleting speed: $0.0013 \mathrm{~m} \cdot \mathrm{s}^{-1}, 0.0021 \mathrm{~mm} \cdot \mathrm{s}^{-1}, 0.0028 \mathrm{~mm} \cdot \mathrm{s}^{-1}$;

- die temperature: $70^{\circ} \mathrm{C}, 80^{\circ} \mathrm{C}, 90^{\circ} \mathrm{C}$.

For each parameter set, three pellets were obtained, and thus, a total of 243 pellet samples were obtained and monitored over time in terms of length expansion. All pellet samples were first allowed to cool completely, were measured and then were placed in individual bags that were numbered and stored at temperatures between $20-25^{\circ} \mathrm{C}$, the pressure between $86-106 \mathrm{kPa}$ and the air moisture of maximum $75 \%$.

Samples were measured using electronic callipers that have a measuring range between $0-100 \mathrm{~mm}$, $0.01 \mathrm{~mm}$ resolution and 0.03 precision.

Pellet length measurements were conducted over a 91 days period, measuring each pellet every 7 days, resulting in 14 total measurements for all sample. In Figure 2 are presented examples of pellet samples that have broken throughout the monitoring period.
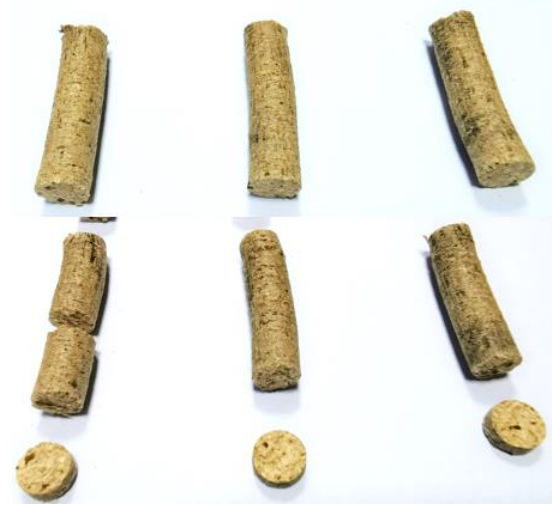

Fig. 2. Examples of broken pellet samples: top-in the first day; bottom - when they broke during the monitoring period 


\section{Results and discussion}

The modifications that occur in the length of pellets over time, from the first day of obtaining them to the last day of monitoring the evolution, represent an important parameter that can offer an overall picture of how and when the pellets tend to stabilize.

In Figure 3 is presented comparatively the variation of the evolution of the length of the pellets obtained with an initial material moisture of $10 \%$ for the three compression forces used.

$10 \mathrm{kN}$

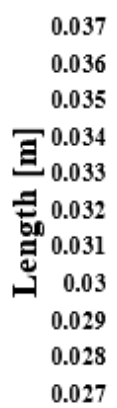

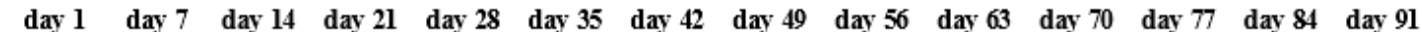

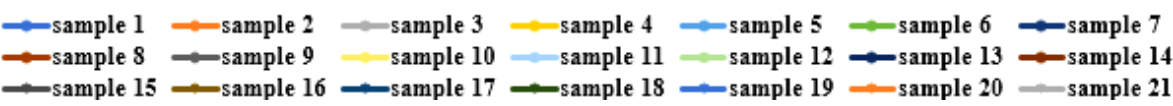

\section{$20 \mathrm{kN}$}

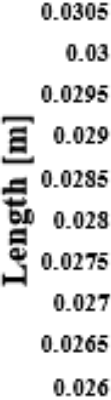

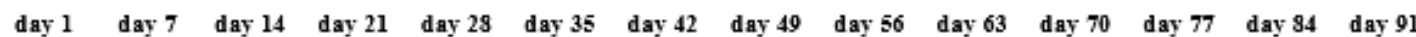

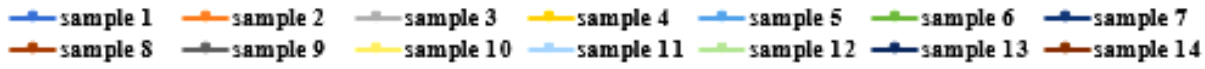

- sample 15 - sample 16 -sample 17 -sample 18 - sample $19-$ sample 20 sample 21

\section{$30 \mathrm{kN}$}

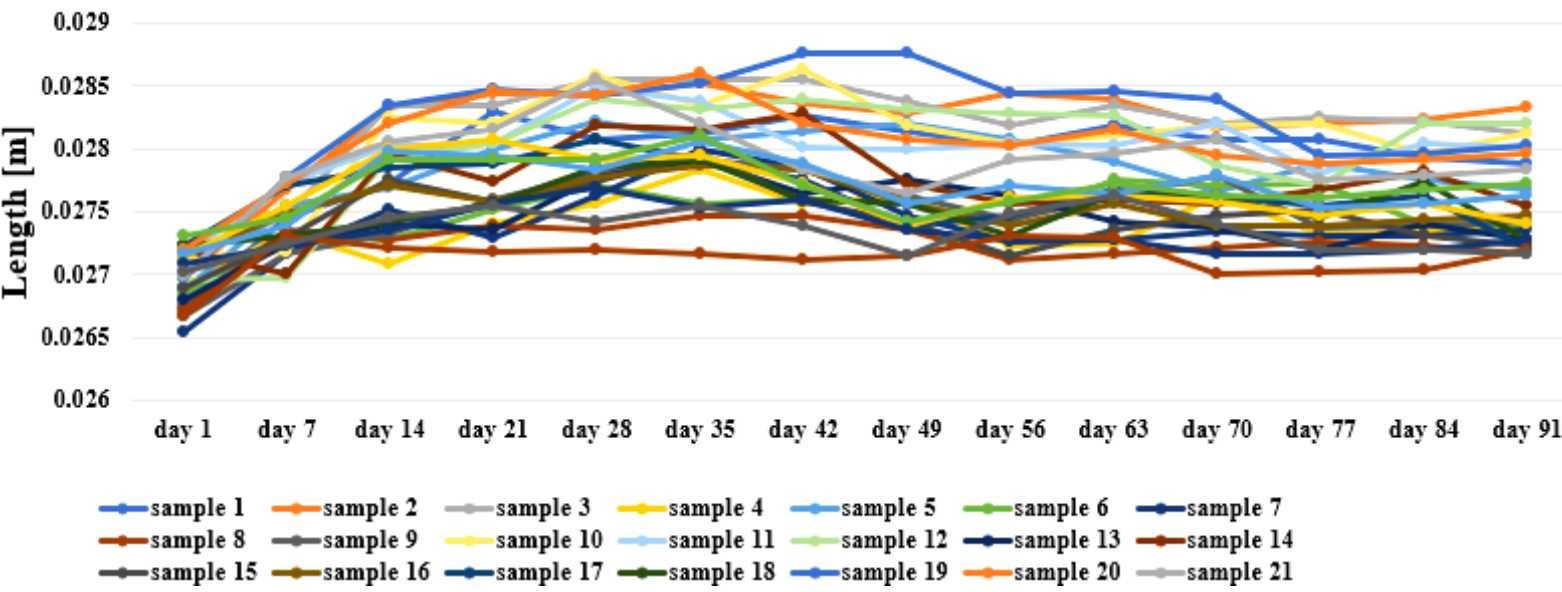

Fig. 3. Evolution of the length of pellets obtained with moisture of $10 \%$, at three compression force speeds used 
From Figure 3 it was found that for all the three compression forces used there was an expansion of the pellets in the first 4 to 6 weeks of monitoring, followed by a stabilization period. No broken pellets were recorded.

Figure 4 presents comparatively the variation of the evolution of the length of the pellets obtained with an initial material moisture of $13 \%$ for the three compression forces used.

$10 \mathrm{kN}$

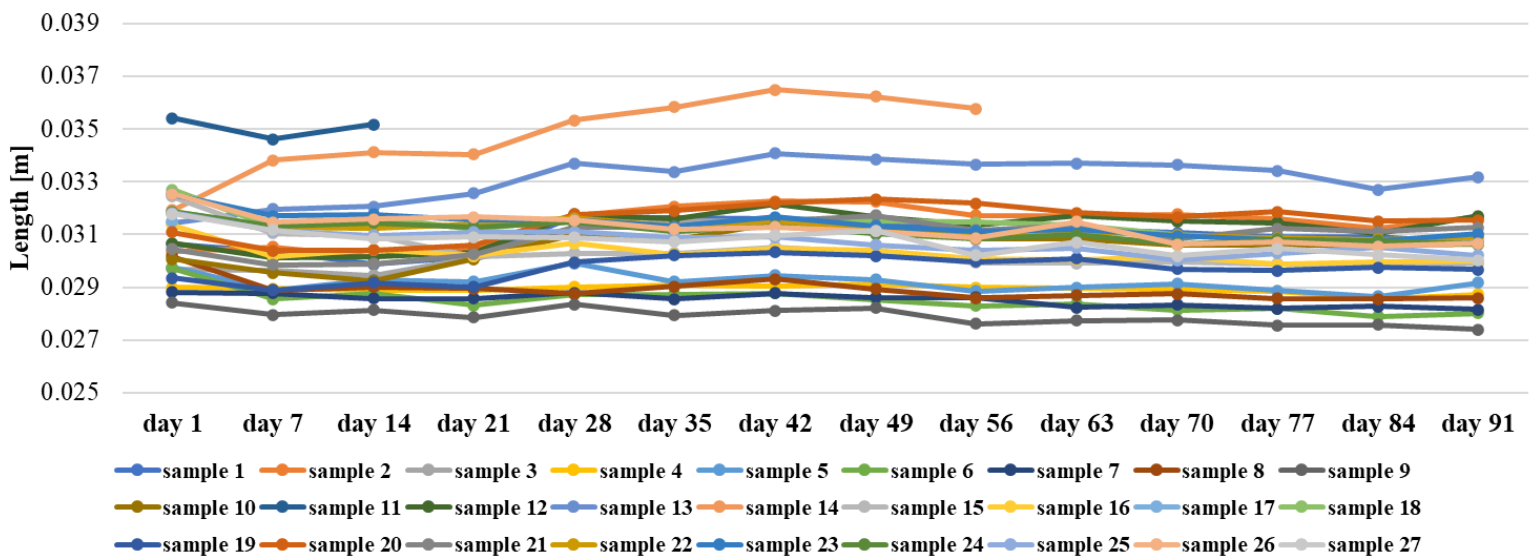

$20 \mathrm{Kn}$

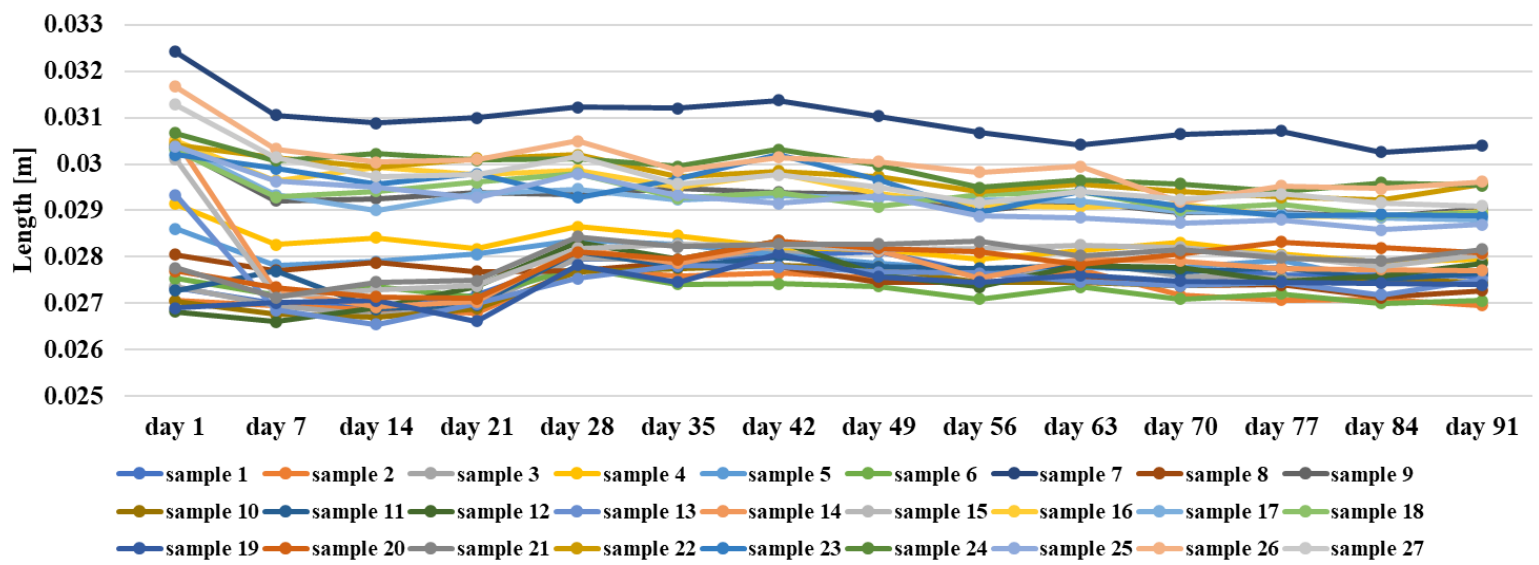

$30 \mathrm{kN}$

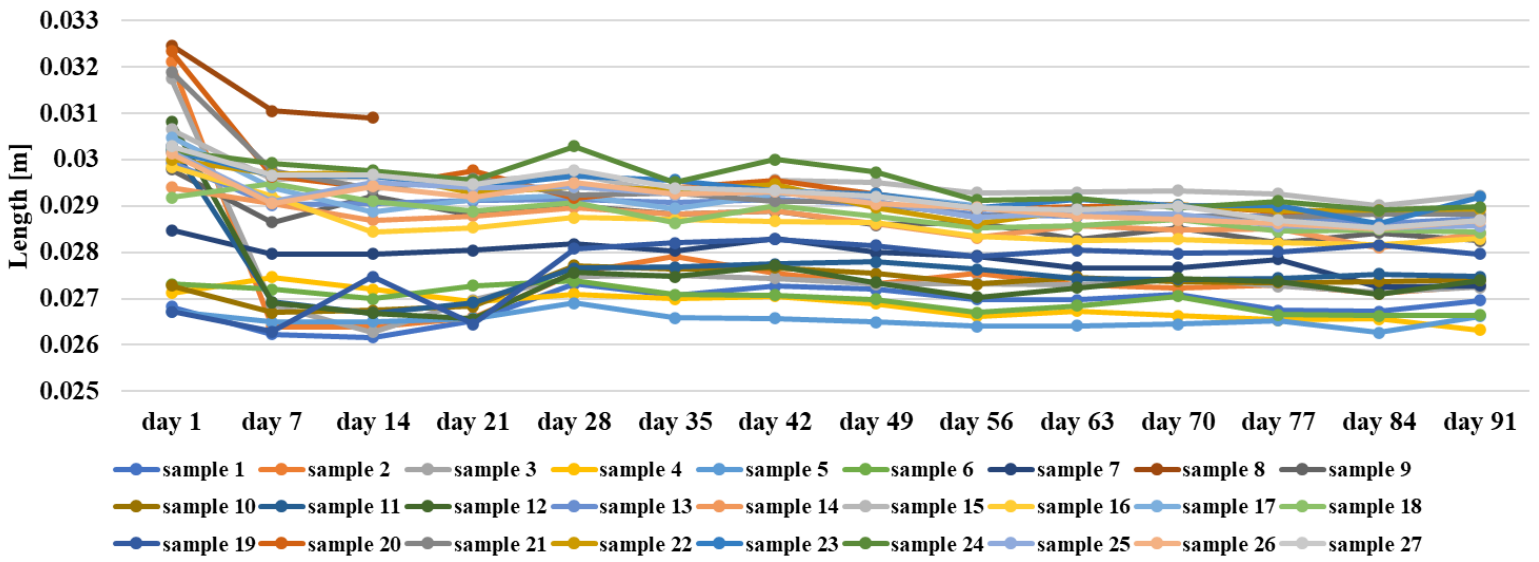

Fig. 4. Evolution of the length of pellets obtained with moisture of $13 \%$, at three compression force speeds used

From Figure 4 it was found that for all the three compression forces used there was an expansion of the pellets in the first week after obtaining them, followed by a stabilization period. A number of 6 broken pellets was recorded. 
Figure 5 presents comparatively the variation of the evolution of the length of the pellets obtained with an initial material moisture of $16 \%$ for the three compression forces used.

$10 \mathrm{kN}$

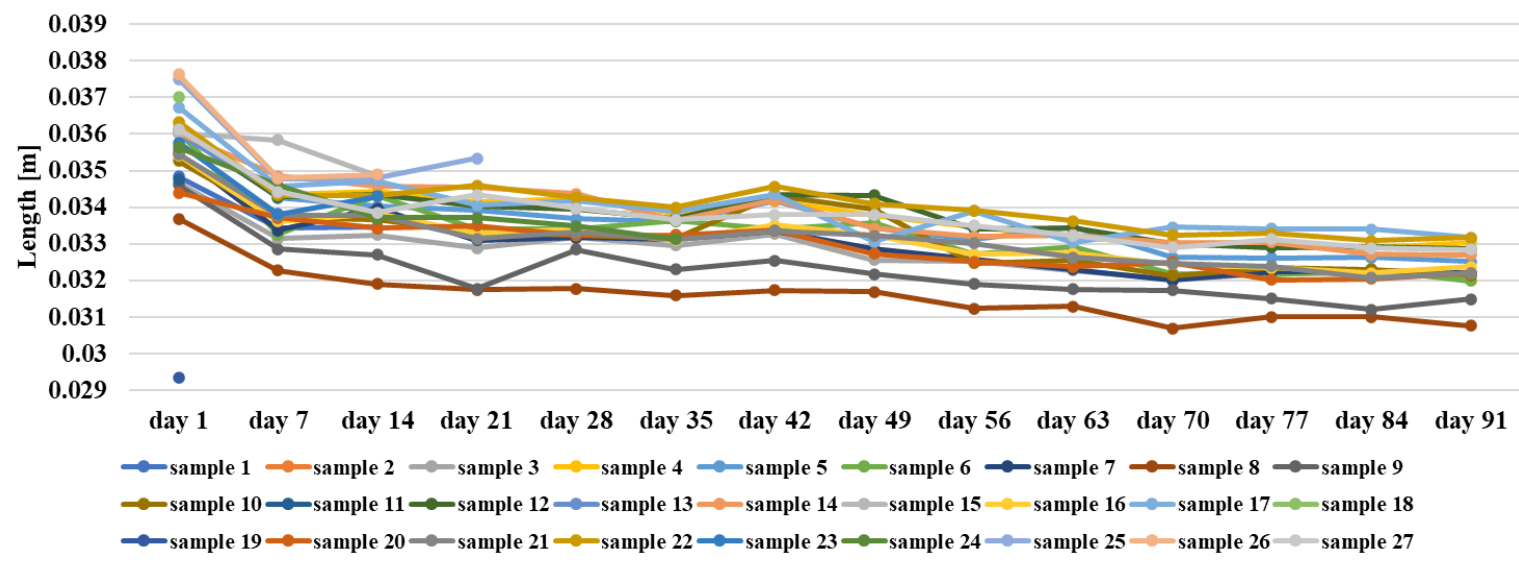

$20 \mathrm{kN}$

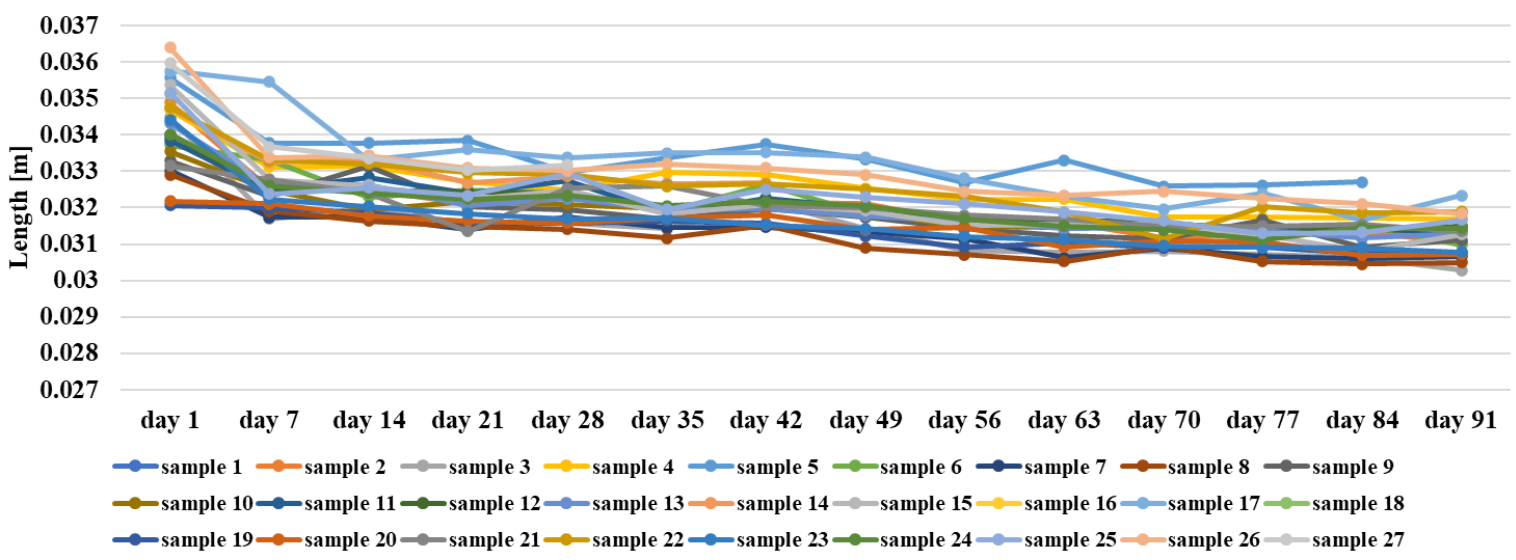

$30 \mathrm{kN}$

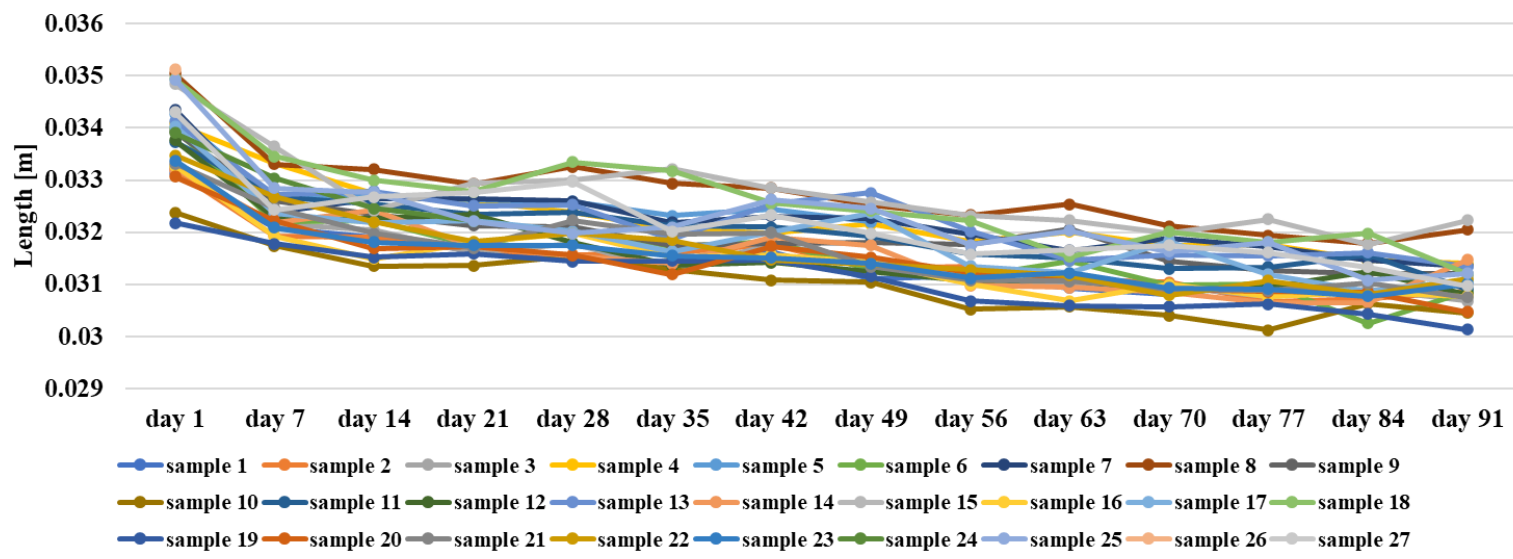

Fig. 5. Evolution of the length of pellets obtained with moisture of $16 \%$, at three compression force speeds used

From Figure 5 it was found that for all the three compression forces used there was an expansion of the pellets in the first week after obtaining them, followed by a stabilization period. A number of 11 broken pellets was recorded for the $10 \mathrm{kN}$ force, 6 for the $20 \mathrm{kN}$ force and 3 for the $30 \mathrm{kN}$, indicating that a bigger force helped maintain the integrity of pellets in time.

Table 1 shows the average changes in the pellet length (expansion or contraction) between day 1 and the last day of monitoring - day 91 (week 14), depending on the compaction forces used. 
Average changes in pellet length between day 1 and day 91

\begin{tabular}{|c|c|c|c|c|c|c|c|c|c|}
\hline \multirow{2}{*}{ Sample } & \multicolumn{3}{|c|}{$10 \%$ moisture } & \multicolumn{3}{|c|}{$13 \%$ moisture } & \multicolumn{3}{|c|}{$16 \%$ moisture } \\
\hline & $10 \mathrm{kN}$ & $20 \mathrm{kN}$ & $30 \mathrm{kN}$ & $10 \mathrm{kN}$ & $20 \mathrm{kN}$ & $30 \mathrm{kN}$ & $10 \mathrm{kN}$ & $20 \mathrm{kN}$ & $30 \mathbf{~ k N}$ \\
\hline 1 & 1.39 & 2.02 & 1.14 & 0.05 & 0.26 & 0.13 & $*$ & $*$ & -2.31 \\
\hline 2 & 1.28 & 2.54 & 1.36 & 1.31 & -0.11 & -4.84 & $*$ & -3.85 & -2.33 \\
\hline 3 & 1.03 & 1.95 & 1.02 & $*$ & 0.06 & -4.5 & -2.53 & -4.21 & -2.56 \\
\hline 4 & 1.39 & 1.92 & 0.49 & -0.27 & -1.19 & -0.8 & -3.25 & -2.99 & -2.68 \\
\hline 5 & 0.64 & 2.16 & 0.81 & -0.57 & -0.89 & -0.1 & -3.63 & $*$ & $*$ \\
\hline 6 & 1.04 & 1.94 & 0.54 & -1.72 & -0.48 & -0.68 & -4.07 & -2.74 & -3.11 \\
\hline 7 & 0.35 & 0.82 & 0.82 & -0.65 & -2.03 & -1.2 & -3.25 & -2.35 & -3 \\
\hline 8 & 0.49 & 0.49 & 0.46 & -1.58 & -0.78 & $*$ & -2.92 & -2.4 & -2.99 \\
\hline 9 & 0.53 & 0.66 & 0.75 & -1.01 & -1.3 & -1.54 & -3.12 & -2.18 & -2.72 \\
\hline 10 & 1.21 & 2.28 & 1 & 0.57 & 0.41 & 0.13 & -3.12 & -2.22 & -1.93 \\
\hline 11 & 1.1 & 1.84 & 0.87 & $*$ & 0.38 & -2.83 & $*$ & -2.53 & -2.82 \\
\hline 12 & 1.2 & 1.61 & 1.25 & 1.05 & 1.05 & -3.43 & -3.2 & -2.52 & -2.95 \\
\hline 13 & 0.61 & 0.7 & 0.47 & 1.75 & -1.82 & -1.21 & $*$ & -3.01 & -2.78 \\
\hline 14 & 0.66 & 0.9 & 0.36 & $*$ & -2.81 & -0.99 & -3.34 & $*$ & -1.75 \\
\hline 15 & 0.74 & 1.02 & 0.34 & -2.55 & -2.06 & -1.42 & $*$ & -4.1 & -2.61 \\
\hline 16 & 0.56 & 0.84 & 0.32 & -1.38 & -1.53 & -1.54 & -3.04 & $*$ & -2.51 \\
\hline 17 & 0.45 & 0.54 & -0.02 & $*$ & -1.61 & $*$ & -3.56 & -3.42 & -2.94 \\
\hline 18 & 0.63 & 0.49 & 0.06 & -1.82 & -1.35 & -0.76 & $*$ & $*$ & -3.74 \\
\hline 19 & 1.62 & 2.87 & 1.05 & 0.33 & 0.5 & 1.24 & $*$ & -1.32 & -2.05 \\
\hline 20 & 1.36 & 2.69 & 0.78 & 0.45 & 0.38 & -3.39 & -2.19 & -1.46 & -2.6 \\
\hline 21 & 1.46 & 2.6 & 0.85 & 0.82 & 0.4 & -3.08 & -3.25 & -1.79 & -2.57 \\
\hline 22 & 0.7 & 1.45 & 0.26 & -0.94 & -0.85 & -1.07 & -3.17 & -2.87 & -2.37 \\
\hline 23 & 0.59 & 0.92 & 0.46 & -1.49 & -1.32 & -0.99 & $*$ & -3.64 & -2.37 \\
\hline 24 & 0.59 & 0.66 & 0.42 & -1.25 & -1.13 & -1.22 & $*$ & -2.58 & -33.9 \\
\hline 25 & 0.37 & 0.43 & 0.19 & -1.63 & -1.68 & -1.61 & -37.5 & -3.49 & -3.72 \\
\hline 26 & 0.2 & 0.55 & 0.53 & -1.87 & -2.05 & -1.45 & $*$ & -4.56 & $*$ \\
\hline 27 & 0.09 & 0.3 & 0.15 & -1.75 & -2.19 & -1.59 & -3.28 & $*$ & -3.33 \\
\hline AVERAGE & 0.82 & 1.38 & 0.62 & -0.61 & -0.88 & -1.55 & -3.18 & -2.86 & -3.95 \\
\hline
\end{tabular}

* - broken pellet samples

From Table 1 it results that pellets obtained at a $10 \%$ material moisture registered an average expansion between 0.62 and $1.38 \mathrm{~mm}$, the largest one for the compaction force of $20 \mathrm{kN}$; pellets obtained with a $13 \%$ material moisture registered an average contraction between 0.61 and $1.55 \mathrm{~mm}$, the largest for the compaction force of $30 \mathrm{kN}$, and for a material moisture of $16 \%$ was registered the biggest overall contraction, between 2.86 and $3.95 \mathrm{~mm}$, also combined with the largest number of broken pellets.

\section{Conclusions}

It was noted that a high moisture of the raw material (16\%) leads to a high moisture of pellets, the loss of moisture through the pelleting process being on average $2.94 \%$, which caused the most disintegrated pellet at this moisture (a total of 19 broken pellets), compared to $10 \%$ material moisture that registered no broken pellets, and the $13 \%$ material moisture where 5 broken pellets were registered. After pellet monitoring, an important difference was found between the three initial material moistures used: pellets obtained at a 10\% moisture registered a growth in length (a relaxation) in the first weeks, followed by a stabilization period; pellets obtained at $13 \%$ and $16 \%$ registered a strong decrease in length in the first week of monitoring followed by stable decrease and a stabilization period. Overall, the pellets obtained at $10 \%$ material moisture had an expansion of $0.62-1.38 \mathrm{~mm}$, while the pellets obtained at $13 \%$ and $16 \%$ material moisture had a contraction of $0.61-1.55 \mathrm{~mm}$, respectively 2.86 $3.95 \mathrm{~mm}$, depending on the pelleting force used. 


\section{Acknowledgements}

This work was supported by a grant of the Romanian Ministry of Agriculture and Rural Development, through ADER Program, project "Technologies for the superior valorisation of lignocellulosic waste from horticulture" contract No. ADER 25.4.2/27.09.2019.

\section{References}

[1] Capareda S. C., Introduction to biomass energy conversions, CRC Press Taylor and Francis Group, ISBN: 978-1-4665-1334-1, 2014.

[2] Găgeanu I., Voicu Gh., Vlăduţ V., Voicea I. Experimental research on the influence of recipes used on the quality of biomass pellets, Proceedings of the 16th International Scientific Conference "Engineering for rural development", Jelgava, Latvia, 2017, pp. 785-791, ISSN 1691-5976.

[3] Ungureanu N., Vlădut V., Voicu Gh., Dincă M., Zăbavă B. Influence of biomass moisture content on pellet properties - Review, Proceedings of the 17th International Scientific Conference "Engineering for Rural Development", Jelgava, Latvia, 2018, pp. 1876-1883.

[4] Vlăduţ V., Chiţoiu M., Danciu A., Militaru M., Lehr C. The Importance of Humidity on Agricultural and Forestry Biomass in the Process of Pellets and Agri-Pellets Production, Bulletin of University of Agricultural Sciences and Veterinary Medicine Cluj-Napoca - Agriculture, nr. 67 (1)/2010, Cluj Napoca - România, pp. 292-300, ISSN 1843-5246.

[5] Ungureanu N., Vlăduţ V., Biriş S.Şt., Dincă M., Ionescu M., Zăbavă B.Şt., Munteanu M.G., Voicea I. A review on the durability of biomass pellets, Proceedings of the 5th International Conference on Thermal Equipment, Renewable Energy and Rural Development, TE-RE-RD 2016, 2016, pp. 417 422, ISSN 2359-7941.

[6] Voicea I., Voicu Gh., Cârdei P., Vlăduţ V., Găgeanu I., Daraban A. Theoretical and experimental research on the process of biomass briquetting, UPB Scientific Bulletin, Series D - Mechanical Engineering, Vol. 78, Issue 3, 2016, pp. 203-214.

[7] Matache M., Vlăduţ V., Danciu A., Voicea I., Pirnă I., Postelnicu E., Chirilă C. Vegetal biomass, a renewable source for obtaining of clean energy, WSEAS International Conferences on Energy, Environment, Economics, Devices, Systems, Communications, Computers (IAASAT) Computational Engineering in Systems Applications, vol. II, Iasi, Romania 2011, pp. 96-100.

[8] Voicea I., Vlăduţ V., Matache M., Danciu A., Voicu Gh. Influence of agricultural and forestry biomass physical characteristics on compacting/pelleting process, Proceedings of the 42nd International Symposium on Agricultural Engineering "Actual Tasks on Agricultural Engineering”, Opatija - Croaţia, 2014, pp. 387-396, ISSN 1333-2651.

[9] Ungureanu N., Paraschiv G., Ionescu M., Zăbavă B.Șt., Vlăduț V., Grigore I. Production status of biomass pellets - Review, Scientific International Conferences - Annals of the University of Craiova - Agriculture, Montanology, Cadastre, Series, Vol. 46, No. 2/2016, pp. 574-581.

[10] Hou Z., Qiu Y., Chen Z., Chen L., Zhiwei S. Numerical simulation and experimental study on pelleting motion law of agropyron seeds under vibration force field, INMATEH -Agricultural Engineering, vol.63 (3), 2020, pp. 299-308, DOI: https://doi.org/10.35633/inmateh-62-31.

[11] Comoglu, T., An Overview of Compaction Equations, Journal of Faculty of Pharmacy, Ankara, 36(2), 2007, pp. 123-133.

[12] Voicea I., Vlăduţ V., Cârdei P., Matache M., Găgeanu I., Voicu Gh., Popescu C., Paraschiv G., Kabas $\mathrm{O}$ - Compacting process and mathematical analysis of miscanthus briquettes expansion, Proceedings of the 43rd International Symposium on Agricultural Engineering "Actual Tasks on Agricultural Engineering”, Opatija - Croaţia, 2015, pp. 667-676, ISSN 1333-2651;

[13] Chiţoiu M., Voicu Gh., Paraschiv G., Moiceanu G., Vlăduţ V., Matache M., Marin E., Bunduchi G., Danciu A., Voicea I., Găgeanu I. Energy consumption of a hammer mill when chopping miscanthus stalks, Proceedings of the 44th International Symposium on Agricultural Engineering "Actual Tasks on Agricultural Engineering", Opatija - Croaţia, 2016, pp. 215-224. 